\title{
Aproximações do Campo-tema Juventude e Violência na Periferia de
}

\section{Fortaleza}

\author{
Veriana de Fátima Rodrigues Colaço* \\ Universidade Federal do Ceará - UFC, Fortaleza, CE, Brasil \\ ORCID: https://orcid.org/0000-0002-7863-4287 \\ Luciana Martins Quixadá*** \\ Universidade Estadual do Ceará - UECE, Fortaleza, CE, Brasil \\ ORCID: https://orcid.org/0000-0001-7082-5698 \\ Jaileila de Araújo Menezes*** \\ Universidade Federal de Pernambuco - UFPE, Recife, PE, Brasil \\ ORCID: https://orcid.org/0000-003-3322-3764 \\ Ana Jéssica de Lima Cavalcante $* * * * *$ \\ Defensoria Pública do Ceará, Fortaleza, CE, Brasil \\ ORCID: https://orcid.org/0000-0002-5848-4082 \\ Raquel Nascimento Sousa****** \\ Universidade Federal do Ceará - UFC, Fortaleza, CE, Brasil \\ ORCID: https://orcid.org/0000-0001-9677-1878
}

\section{RESUMO}

Este artigo tem o propósito de trazer reflexões sobre violência urbana e violação de diretos fundamentais como acontecimentos que têm marcado o cotidiano de adolescentes e jovens residentes na periferia de Fortaleza. Também traz uma discussão sobre os desafios metodológicos das pesquisas participativas com esse público. O Estado do Ceará e, principalmente, sua capital têm apresentado os maiores índices de homicídios de adolescentes nos últimos anos, e os índices estão crescendo entre as meninas. Embora tenham ocorrido intervenções dos órgãos nacionais e latino-americanos de Direitos Humanos, com ações judiciais interpostas por entidades que atuam na defesa de direitos de crianças, adolescentes e jovens, os poderes executivo, judiciário e legislativo se mobilizam, quase sempre, oferecendo respostas paliativas à população, e propõem ações de controle e repressão para o fortalecimento do projeto político neoliberal. Nesse cenário, importa refletir sobre os efeitos da dinâmica territorial da violência na vida de jovens da periferia, os dispositivos que compõem a rede de controle/enfrentamento à violência e seus impactos na construção de lentes teórico-metodológicas que instrumentalizem os/as pesquisadores/as ao manejo da produção de conhecimento no campo-tema juventude-violência.

Palavras-chave: violência, território, juventude, necropolítica.

ISSN 1808-4281 


\title{
Approaches of the Youth and Violence Field in the Periphery of Fortaleza
}

\begin{abstract}
This article aims to bring reflections on urban violence and violation of fundamental rights as events that have marked the daily lives of adolescents and young people living in the outskirts of Fortaleza. It also brings a discussion about the methodological challenges of participatory research with this audience. The state of Ceará and, especially, its capital, has had the highest rates of homicide among adolescents in recent years, and rates are growing among girls. Although interventions by national and Latin American Human Rights bodies have taken place, the judicial and legislative powers are mobilized, based on lawsuits filed by entities that defend and guarantee the rights of children, adolescents and youth, offering palliative responses to the population, and, mainly, they to propose measures of control and repression, which ensure the strengthening of the neoliberal political project. In this scenario, it is important to reflect on the effects of the territorial dynamics of violence on the life of young people from the periphery, the devices that make up the network of control / coping with violence and its impacts on the construction of theoretical and methodological lenses, that equip the researchers to manage knowledge production in the youth-violence field.
\end{abstract}

Keywords: violence, territory, youth, necropolitics.

\section{Aproximaciones del Campo-tema Juventud y Violencia en la Periferia de}

\section{Fortaleza}

\begin{abstract}
RESUMEN
Este artículo tiene el propósito de traer reflexiones sobre violencia urbana y violación de derechos fundamentales como acontecimientos que marcan el cotidiano de adolescentes y jóvenes residentes en la periferia de Fortaleza. También trae un debate sobre los desafíos metodológicos de la investigación participativa con este público. El Estado de Ceará y, principalmente su capital, ha presentado los mayores índices de homicidios de adolescentes en los últimos años, las cifras continúan creciendo. Aunque se han producido intervenciones de los órganos nacionales y latinoamericanos de Derechos Humanos, con acciones judiciales interpuestas por entidades que actúan en la defensa de derechos de niños, adolescentes y jóvenes, los poderes ejecutivo, judicial y legislativo se movilizan en la perspectiva de ofrecer respuestas paliativas a la población, y se empeñan en proponer acciones de control y represión, que aseguren el fortalecimiento del proyecto político neoliberal. En este escenario, es importante reflexionar sobre los efectos de la dinámica territorial de la violencia en la vida de jóvenes periféricos, los dispositivos que componen la red de control/enfrentamiento a la violencia y sus impactos en la construcción de lentes teórico-metodológicas que instrumentalicen adecuadamente a los/las investigadores/as para el manejo de la producción de conocimiento en el campo-tema juventudviolencia.
\end{abstract}

Palabras clave: violencia, territorio, juventud, necropolítica. 
Este artigo tem o propósito de trazer algumas reflexões sobre a problemática vivida por adolescentes e jovens que são alvo de violência urbana e violação de direitos fundamentais, sem que haja um efetivo enfrentamento do Estado - que não lhes assegura esses direitos, nem mobilizações da população em geral, no sentindo de promover e exigir do Estado ações para reverter essa realidade. $\mathrm{O}$ artigo também visa discutir os desafios de fazer pesquisa participativa, especificamente pesquisa-intervenção, com esse público. Essas reflexões foram formuladas a partir das tentativas de diálogo com jovens em um território de periferia urbana, por ocasião de estudo desenvolvido por uma equipe de pesquisadoras, que foi formada com a parceria entre dois Grupos de pesquisa de instituições diferentes.

O Estado do Ceará, particularmente sua capital Fortaleza, têm apresentado os maiores índices de homicídios de adolescentes nos últimos anos, com agravamento em 2017 e também em 2018, com lamentável expansão com relação às meninas (Comitê Cearense pela Prevenção de Homicídios de Adolescentes (CCPHA), 2018; Cerqueira et al, 2018). Embora tenham ocorrido intervenções dos órgãos nacionais e latino-americanos de Direitos Humanos, a partir de ações judiciais interpostas por entidades que atuam na defesa e garantia de direitos de crianças, adolescentes e jovens, os poderes executivo, judiciário e legislativo se mobilizam, quase sempre, na perspectiva de oferecer respostas apressadas e paliativas à população, e principalmente, empenham-se em propor ações de controle e repressão, que assegurem a manutenção e o fortalecimento do projeto político neoliberal vigente.

Vale ressaltar que esse fenômeno da intensificação da violência urbana passou a configurar o foco de atenção dos institutos de pesquisas de opinião e do Instituto Brasileiro de Geografia e Estatística (IBGE), cujos censos sociodemográficos mais pormenorizados fornecem elementos de análises estatísticas sofisticadas, que possibilitam, por exemplo, a divulgação mais frequente do Mapa da Violência no Brasil (Waiselfisz, 2016), a publicação do Atlas da Violência de 2018 (Cerqueira et al, 2018) e dados do Fórum Brasileiro de Segurança Pública (FBSP) (2016).

A magnitude do tema da violência urbana e sua visibilidade estatística têm repercutido na produção acadêmica sobre essa problemática, congregando várias áreas de conhecimento e promovendo um diálogo entre perspectivas quantitativas e qualitativas de pesquisas. Ressaltamos o papel das pesquisas participativas por sua potência de convocar à produção de conhecimento aqueles/as que comumente são tomados/as como objetos de estudos, sobre quem, muitas vezes, 
os/as pesquisadores/as falam sem o devido cuidado e sem promover condições favoráveis para a escuta legítima das experiências desses sujeitos, em especial quando são jovens e têm seu saber deslegitimado pelo estigma geracional.

Em se tratando de jovens pobres e negros/as, a opressão que recai sobre suas vidas é ainda mais intensa e fica evidente pelo lugar paradoxal que ocupam, ou seja, de um lado, são percebidos/as como responsáveis pelo aumento da violência (discurso midiático e do senso comum) e, de outro, são vítimas brutais da violência urbana, como atestam os índices estatísticos e os resultados das pesquisas científicas críticas. Isso evidencia a persistência do racismo, do preconceito e da exclusão social de uma determinada parcela da população, que vem se acentuando na sociedade brasileira atual, com um retrocesso para o conservadorismo e o acirramento de valores e ideias reacionários. Nesse processo de acirramento de valores morais conservadores, declara-se abertamente a intenção de que esse segmento populacional seja eliminado, seja pelo encarceramento/privação de liberdade, ou simplesmente sendo executado.

Em 2014, segundo o Relatório da pesquisa do Comitê Cearense pela Prevenção de Homicídios na Adolescência (2016), o Conselho Nacional do Ministério Público “[...] registrou a presença de 23.658 meninos e meninas em cumprimento de medidas de privação e restrição de liberdade em 82,5\% das unidades inspecionadas. Destes, 21.823 cumprem medida socioeducativa de internação, enquanto 1.835 estão em regime de semiliberdade nos 443 centros educacionais superlotados do país - a capacidade é para atender 15.414.” (p. 495). Estes dados, que são de 2014, já apontavam um imenso contingente de adolescentes encarcerados e em condições de superlotação nas unidades, o que, por si só, já implica violação de direitos por parte do Estado.

Neste sentido, podemos compreender como o racismo opera disfarçadamente, sob a justificativa de estar protegendo a sociedade da violência urbana, excluindo do convívio social os “indesejáveis”. Assim explicam Mayorga, Diniz, Pinto, Borges e Rodrigues (2015):

Segundo o movimento negro, o genocídio da juventude negra é a síntese do racismo brasileiro contemporâneo que, através do Estado, organiza a gestão da vida social e política para promover sistematicamente o extermínio cultural e físico da população negra. Os índices alarmantes de mortes, em todos os estados do país, nos grandes centros urbanos e nas cidades do interior, a crescente marginalização da juventude negra e de periferia, as desigualdades de gênero e a desqualificação da religiosidade afro-brasileira 
são alguns problemas que marcam a experiência dessa juventude. (Mayorga, et al., 2015, pp. 76)

Como protagonista dessa condição social paradoxal, o jovem pobre e negro, na grande maioria do gênero masculino, das periferias urbanas aparece como autor e vítima do crescimento da violência, e se tornou um dos principais assuntos dos discursos políticos, científicos e policiais. Entretanto, há que se questionar: como esse jovem compreende essa realidade e como vem reagindo a ela, isto é, quais os canais de escuta e organizações coletivas de que dispõe para o seu enfrentamento e como vem se constituindo subjetivamente a partir dessa percepção negativa a seu respeito? E, ainda, se e como tem reagido diante deste cenário social? Com estes questionamentos, nossa paulatina inserção no campo-tema de pesquisa conduziu-nos à formulação da seguinte pergunta norteadora deste estudo: como jovens negros, excluídos da escola e de outros equipamentos sociais de Fortaleza, significam e reagem ao racismo, à exclusão social e à ameaça à própria vida?

É necessário esclarecer que, neste artigo, não pretendemos apresentar os resultados do estudo que esta questão originou, até porque ele ainda está em fase de análise, e sim problematizar o fazer pesquisa com este público e apresentar as bases teórico-metodológicas que estamos adotando sobre essa complexa problemática e suas implicações no campo da investigação em Psicologia.

Consideramos o processo histórico de colonização dos povos subalternos como base para explicações sobre a condição de exclusão e marginalização social, que precisa ser focada pela análise articulada dos variados fatores que estão subjacentes à sua produção, tais como raça, gênero, classe social, geração e local de moradia. Ou seja, procuramos compreender as interações entre esses marcadores sociais, subsidiadas pela perspectiva da interseccionalidade. Pensar, pesquisar, analisar interseccionalmente implica interrogar os marcadores sociais "como forças ativas da constituição do que somos, como eixos de diferenciação e, mais, de subordinação, que terminam por constituir nossas identidades, nossa diferença, bem como nossas estratégias de luta" (Werneck, 2014, p. 321).

Advogamos as contribuições da pesquisa-intervenção como dispositivo fundamental para a construção de possibilidades de escuta em "outra língua", onde os/as pesquisadores/as se dedicam a fazer pesquisa em uma dimensão mais ampla de produção de conhecimento, 
oportunidade para intercambiar informações qualificadas que podem contribuir para o entendimento das desigualdades sociais. Considerando as violências que incidem sobre a juventude negra, por exemplo, o papel das ações afirmativas em nosso país e a luta de grupos e movimentos sociais podem ser tomados como importantes temas de debate com os/as jovens, que propiciam a construção de um campo semiótico onde outras possibilidades de ser e existir na condição de jovem negro/a se colocam para além da violência propriamente dita.

A proposta metodológica do estudo, de base qualitativa, foi interventiva e operacionalizada com inserção no campo, observação participante e aproximação gradual e progressiva com os/as jovens. Frente a suas experiências de desqualificação, exclusão e violência explícita, os poucos jovens (todos do sexo masculino) protagonistas deste estudo apresentavamse desconfiados, reticentes e resistentes para participar de um trabalho de pesquisa com eles. Por esta razão, a proposta que tinha sido delineada metodologicamente para a pesquisa ficou em suspenso e tivemos que nos colocar abertas para procedimentos não ortodoxos e paulatinamente construídos no contato com o campo-tema.

A noção de campo-tema tem se mostrado fundamental para a compreensão do que vivemos e posteriormente pretendemos comunicar sobre os desafios do fazer pesquisa em Psicologia com jovens pobres e negros, residentes na periferia da cidade de Fortaleza. Pesquisar na periferia e em contexto de diversas violências tem implicado em ocupar uma posição periférica no campo, ou seja, chegar pelas bordas, pisando com cuidado e com atenção às dinâmicas que existem e desafiam o saber acadêmico. Uma das principais tarefas é (re)afirmar o propósito de nosso "Estar lá" (Geertz, 2008), ou seja, a dimensão de compromisso de nosso trabalho e também o aprendizado de que "ser parte do campo-tema não é um fim de semana de pesquisa participante e muito menos uma relação de levantamento de dados conduzido num lugar exótico" (Spink, 2003, p. 27). Ocupar a periferia do campo implica também admitir a pesquisa como processualidade, em que nossos relatos do "Estar lá", as conversas que estabelecemos, os detalhes que buscamos são parte do processo de nos inserirmos no campo-tema, em seu complexo de redes de sentidos e em suas teias de ação (Spink, 2003).

Assim, interessava-nos estabelecer condições para realizarmos entrevistas narrativas e grupos de discussão com jovens, que se apresentavam na margem externa de um Centro Urbano de Cultura, Arte, Esportes e Ciências (CUCA) e que participavam informalmente de uma atividade denominada "Roda do Chá". Com este estudo, esperamos contribuir para ampliar as 
análises sobre juventude, relações étnico-raciais e violência urbana, tendo como foco a visão desses atores sociais frente a um contexto hostil, preconceituoso e discriminador, que aponta perspectivas excludentes e até mesmo de eliminação, particularmente do/a jovem negro/a e pobre.

O artigo está dividido em três partes que, tendo por fundamento conceitos como colonialidade, biopolítica e necropolítica, trazem para discussão categorias que percebemos nesse processo de aproximação e que identificamos como racismo institucional, conflitos de territórios e as dimensões de proteção e exclusão das políticas públicas direcionadas aos/às jovens de bairros da periferia de Fortaleza.

\section{Política de Território/Território da Política}

Historicamente no Brasil a violência urbana é perpassada por conflitos territoriais, disputa de poder do tráfico de drogas e armas e os/as moradores(as) de áreas afetadas pela violência convivem com a falta de saneamento básico e outras carências que retratam a presença frágil do Estado. Essas comunidades ganham notoriedade por apresentarem os menores Índices de Desenvolvimento Humano (IDH), além das maiores taxas estatísticas nas questões de pobreza e homicídios, compondo um território estigmatizado.

O território físico do nosso campo-tema foi o bairro Jangurussu, localizado na Secretaria Executiva Regional VI (SER VI), da cidade de Fortaleza, que possui cerca de 600 mil habitantes, dos quais $50 \%$ da população têm até 22 anos, e abrange 29 bairros, correspondendo a $42 \%$ do território da cidade (Instituto de Pesquisa e Estratégia Econômica do Ceará [IPECE], 2013). É uma das regionais mais pobres, ocupando o topo de índices como o maior número de analfabetismo, além das altas taxas de mortes violentas e homicídios (IPECE, 2013).

Em novembro de 2015, a região foi palco de uma chacina que ficou conhecida por "Chacina do Curió", quando foram assassinadas 11 pessoas, em sua maioria jovens de até 29 anos. As investigações apontaram que a autoria desse massacre foi o Estado, na figura da Policia Militar ("Chacina da Messejana", 2016), porém mais de três anos já se passaram e ainda não foram concluídas todas as investigações, que poderiam levar à responsabilização e consequente punição dos verdadeiros autores do crime. 
De acordo com dados da Célula de Vigilância Epidemiológica da Secretária Municipal de Saúde e do Comitê Cearense pela Prevenção de Homicídios na Adolescência (CCPHA) ${ }^{1}$, em 2015 e 2017 o bairro Jangurussu esteve em primeiro lugar no número de homicídios, ficando também em primeiro lugar no número de assassinato de adolescentes. Os agentes públicos responsáveis pela gestão da Segurança Pública no Estado atribuem à "guerra entre facções" o problema do crescimento da violência, retirando a responsabilidade do Estado com um discurso que sustenta o atual status quo da sociedade capitalista, elitista e excludente. Além disso, buscam justificativas simplistas para a onda de assassinatos de jovens, em geral invertendo o foco das atenções para o envolvimento de jovens com drogas ou crime organizado, transformando as vítimas em culpados pela própria morte, ou seja, respaldando ações de violência letal para sujeitos que podem ser mortos. Tal fenômeno encontra ressonância no que Mbembe (2011) destaca, indicando que a concentração de assassinatos nesses territórios não acontece por coincidência. O necropoder utiliza a morte/homicídio como uma ferramenta para exercer o domínio em territórios tidos como ameaçadores, ou seja, as populações mais pobres devem ser dominadas ou eliminadas.

Considerando o fenômeno da violência em rede, em Fortaleza e no Estado do Ceará veem-se as repercussões de um projeto de sociedade historicamente construído e com um marco significativo no ano de 2010, quando das ocupações da Polícia Militar nas comunidades do Rio de Janeiro e o aumento no número de pessoas dentro do sistema carcerário. Esse acontecimento impulsionou a nacionalização das facções criminosas, sendo o Nordeste um dos principais destinos de grupos como o Primeiro Comando da Capital (PCC), oriundos de São Paulo, e o Comando Vermelho (CV), que surgiu no Rio de Janeiro.

Segundo Santos, Jorge e Souza (2017), um dos fatores que explica a expansão e a consolidação das facções criminosas nas periferias é a morosidade da justiça brasileira, o que agrega injustiças sociais e violações dos Direitos Humanos e divide os indivíduos em categorias de subalternidades e indesejados:

Essa estrutura de cidadania hierarquizada teria favorecido a consolidação do PCC enquanto poder político-jurídico nas periferias da capital paulista. Isso porque a facção criminosa estabeleceu um sistema de regulação normativa que exerce sua autoridade não apenas sobre a conduta de criminosos, mas também sobre os cidadãos subintegrados que 
residem nas periferias de São Paulo, e que recorrem ao PCC em busca de algum tipo de justiça. E o dispositivo criado pela facção criminosa para resolver litígios e punir os desvios de conduta são os debates ou tribunais do crime. (Santos et al., 2017, pp. 112)

Desta forma, as facções criminosas chegam para ocupar o espaço onde o Estado deixou lacuna, o que é traduzido de forma clara por letras de músicas criadas pelos/as jovens, do gênero funk, que são escutadas no território onde estamos realizando a pesquisa, como por exemplo na frase "quando o estado não chega o crime adota".

No Ceará, a territorialização das facções foi intensificada no ano de 2012, após uma greve da Polícia Militar, o que agudizou a fragilidade da Segurança Pública no Estado e deu abertura para que as facções criminosas conquistassem novos territórios, quando o número de homicídios bateu recordes, aumentando a cada ano. Entretanto, é importante demarcar que houve uma queda abrupta desse número no ano de 2016. Essa queda é explicada por jovens e moradores do território do Jangurussu como decorrente da "pacificação" dos territórios em Fortaleza. Regras e prescrições foram instauradas pelos comandos, como por exemplo: "é proibido roubar na comunidade". A sensação de segurança nos territórios aumentou, o que foi ratificado por um dos jovens com quem dialogamos, que faz o seguinte comentário: "na pacificação a gente podia andar por qualquer lugar, visitei parentes, que antes eu não podia”. Essa forma de atuar nas comunidades é legitimada pelos moradores, uma vez que produz uma sensação de justiça que foi negada durante anos pelo Estado, além de ser uma estratégia de poder, pois a morte é a punição para quem não cumpre as regras.

O pacto foi quebrado em 2017 e uma série de rebeliões em presídios, com diversos assassinatos brutais em alguns estados do Brasil, levaram à ruptura. As informações que nos foram passadas nas conversas espontâneas com educadores sociais e outros profissionais do equipamento onde estávamos realizando a pesquisa dão conta de que o PCC e Comando Vermelho tornaram-se concorrentes, e a ordem passou a ser exterminar os sujeitos rivais. Nesse contexto, novas facções passaram a ocupar os territórios do Ceará, como a Família do Norte (FDN), oriunda do Pará e que se aliou ao Comando Vermelho, e a Guardiões do Estado (GDE), uma facção nascida no Estado do Ceará, na comunidade Conjunto Palmeiras, que faz parte do Grande Jangurussu e que se aliou ao PCC para ganhar força no Estado e nos presídios cearenses. 
O trânsito pelo território foi findado, e a ordem tornou-se executar quem residia em territórios rivais. Segundo um dos jovens participantes da pesquisa, "a pacificação foi apenas uma estratégia para conquistar novos territórios, tipo o War [jogo de tabuleiro]”. Hoje a Regional VI e o Grande Jangurussu são divididos, principalmente, entre CV e GDE. Segundo Ferreira, Vasconcelos e Penna (2008), as organizações criminosas ocupam e tomam esses locais e passam a articular as ações, dizendo quem pode transitar, formando um exército com a população já criminalizada e sem oportunidades.

O crime organizado arma a população para servir aos seus propósitos e a submete; traz os jovens para seu serviço e os descarta quando bem entende. Os confrontos com o estado geram violência e os conflitos dentro da sociedade armada, facilmente se transformam em homicídios. Dessa forma, a violência e os homicídios aumentam. (Ferreira, Vasconcelos, \& Penna, 2008, pp. 4)

Essas ações e disputas transformadas em números indicam que no ano de 2017 houve um total de 5.134 homicídios no Ceará, sendo quase 2.000 na cidade de Fortaleza, um aumento de mais de $90 \%$ em comparação ao ano de 2016, conforme dados do Comitê Cearense pela Prevenção dos Homicídios na Adolescência (CCPHA, 2016).

A demonstração de poder através dos homicídios, muitas vezes com requintes de crueldade, tem sido o principal instrumento utilizado pelas facções em Fortaleza para dominar uma comunidade. Há pouca bibliografia acerca da história das facções no Ceará, mas o relato oral de jovens e moradores desses territórios contribui para a compreensão de sua atuação. A GDE é a mais jovem organização criminosa com atuação no Estado, sendo seu surgimento datado de 2016. Não há cobrança de taxa de inscrição, o que atrai muitos adeptos, em sua maioria adolescentes e jovens. A demonstração de poder e crueldade nos homicídios praticados é uma das formas de ascensão dentro da facção como, por exemplo, a prática de filmar os crimes e colocar nas redes sociais, além da prática da decapitação. Em janeiro de 2018 ocorreu a maior chacina já registrada no Estado, a "chacina das Cajazeiras", quando 14 pessoas foram mortas e cerca de 15 foram feridas, em uma casa de show no bairro Cajazeiras - por isso o nome da chacina. Tal ação foi atribuída, por moradores anônimos, a essa organização criminosa. 
O que se observa facilmente, com a inserção nesses territórios, é que a mobilidade urbana da população é cerceada por esses grupos. Direitos básicos são violados com o apoio velado do Estado, que ora atribui o problema a essas facções, ora nega sua existência. Os territórios passam a ser espaços de risco principalmente para os jovens negros do gênero masculino, com o aumento da exclusão social, da estigmatização dos territórios e do enfraquecimento das políticas públicas. Marcado por um contexto de opressão, pobreza e domínio do crime organizado, os territórios têm se tornado também um fator de risco para a violência contra a juventude negra e periférica.

\section{Violência, Juventude e Periferia sob as Lentes da Necropolítica}

A expressão "Faixa de Gaza" é utilizada pelo menos desde a década de 1990 para caracterizar a disputa por territórios pelo tráfico de drogas nas grandes cidades de nosso país. O tópico anterior nos ajuda a especificar o tipo de violência que está presente nas periferias da cidade de Fortaleza e tem dizimado a população jovem do local. As estatísticas são de guerra e as limitações existenciais são diversas, impactando inclusive no direito mais básico de ir e vir, de circular pela cidade. Estabelece-se para aqueles que ainda não estão presos no sistema penitenciário a própria prisão territorial.

O conceito de necropolítica, notadamente a partir dos diálogos entre as obras de Foucault e Mbembe, tem se mostrado relevante para o entendimento das dinâmicas de violência e racismo no território investigado, particularmente como uma das facetas de atuação do estado neoliberal. No livro "Em Defesa da Sociedade", Foucault (2016) descreve que o racismo de estado é um racismo institucional, que se refere à legitimação de processos de exclusão social, econômica e política de uma parcela da população. Esse racismo, segundo Foucault, é relativo a um corte estabelecido na definição de quem deve viver e quem deve morrer, sendo produzido e mantido através de mecanismos e tecnologias de poder estatais que se voltam ao controle da vida e da morte graças à emergência de um biopoder.

No contínuo biológico da espécie humana, o aparecimento das raças, a distinção das raças, a hierarquia das raças, a qualificação de certas raças como boas e de outras, ao contrário, como inferiores, tudo isso vai ser uma maneira de fragmentar esse campo do 
biológico de que o poder se incumbiu; uma maneira de defasar, no interior da população, uns grupos em relação aos outros. (Foucault, 2016, pp. 214).

Entendemos que essa produção do conceito de biopoder trata-se de uma denúncia acerca do poder instaurado sobre o campo biológico, de fazer viver e deixar morrer (Foucault, 2016). Nesse sentido, trata-se mais de um controle sobre a vida, garantindo-a para alguns, através de mecanismos estatais discriminatórios e do disciplinamento dos corpos, tornando-os úteis e dóceis, sendo tais processos decorrentes do desenvolvimento de tecnologias de disciplina gestadas na modernidade e que, para Foucault, substituem o exercício do poder soberano, aqui entendido como fato social em antigos regimes monárquicos.

Mbembe (2017), no entanto, aprofunda essa ideia de poder soberano, retomando-a sob outra perspectiva, e desenvolve criticamente o conceito de biopoder, cunhando o termo necropolítica, mas concorda com Foucault quando este defende que o racismo é uma invenção, uma tecnologia criada para permitir o exercício do biopoder: "Na economia do biopoder, a função do racismo é regular a distribuição da morte e viabilizar as funções criminosas do Estado." (Mbembe, 2017, p. 117).

$\mathrm{Na}$ prática, esse racismo institucional pôde ser verificado mais de perto em uma observação feita em uma das ocasiões do nosso estudo. Estávamos na área externa ao CUCA Jangurussu quando houve uma forte movimentação entre os jovens que costumavam transitar no entorno desse equipamento municipal, mas não participavam das atividades formais do mesmo. O que aconteceu nesse momento foi uma "batida policial" que abordou um desses jovens, quando os demais perceberam e correram rapidamente, sendo que dois deles sentaram-se ao lado de duas pesquisadoras da nossa equipe. Uma delas, ao perceber que os policiais estavam com armas em punho e apontadas para os jovens, fez menção de se levantar, mas o jovem ao seu lado segurou-a pelo braço e disse “A 'tia' não sai daqui! A ‘tia' fica aqui!". Foi quando entendemos que o fato deles estarem ao nosso lado garantia-lhes alguma segurança. Depois eles pediram para que os acompanhássemos até um local onde eles pudessem correr dali. Quais sentidos eles tinham sobre aquela situação, que parecia certificar que estar conosco lhes traria segurança? Em que nós nos distinguíamos do jovem abordado violentamente pela polícia? Esta ocorrência nos mobilizou na perspectiva de entender como os marcadores que definem diferenças, que produzem desigualdades, são visibilizados rapidamente pela polícia e pelos jovens, tais como cor da pele, 
vestimentas e outras características que identificam as pessoas consideradas alvo dos extermínios juvenis.

Em sua obra "Políticas da Inimizade", Mbembe (2017) enfatiza o extermínio de populações, de grupos étnico-raciais, sendo o poder soberano exercido tanto pelo Estado (monárquico ou não), como também por milícias urbanas ou exércitos privados, pois "[...] todos reivindicam o direito de exercer violência e de matar" (Mbembe, 2017, p. 140). Para ele, é um poder que se constrói sob o viés do temor à morte e às suas condições de possibilidade, salientando que o terror não é algo da modernidade, mas que, historicamente, tem sido utilizado como instrumento fundamental na política. Apesar disso, ele reconhece que

Se o poder ainda depende do apertado controle dos corpos (ou da sua concentração em campos), as novas tecnologias estão menos preocupadas em inscrever os corpos no aparelho disciplinar, do que em inscrevê-los, a seu devido tempo, na ordem da máxima economia, hoje em dia representada pelo 'massacre'. (Mbembe, 2017, pp. 144)

Nesse exercício do poder soberano estabelecem-se as fronteiras entre o direito à vida e a condenação à morte ou à exclusão, em um controle alimentado pelo medo de ocupar o lugar do Outro que sofre e que morre, isto é, pela negatividade da minha relação com esse Outro: sobrevivo enquanto ele sucumbe. Mbembe (2017), parafraseando Elias Canetti, destaca que "o sobrevivente é aquele que, tendo estado à beira da morte, sabendo de outras mortes, e erguido entre os caídos, ainda está vivo. Esta é a razão pela qual, até certo ponto, matar é a maneira mais econômica de sobreviver." (Mbembe, 2017, p. 145). Provavelmente aí reside o cerne que sustenta as políticas e máquinas de guerra, que atacam e massacram determinados grupos populacionais.

Racismo, nessa perspectiva, é uma categoria situada a partir de narrativas de dominação e emancipação, ou seja, em uma cadeia simbólica e, portanto, não natural, elaborada para garantir ocupações territoriais, econômicas e de sobrevivência, sujeitando a verdade e o direito a uma invenção simbólica, regida de acordo com essas duas lógicas. Isso nos remete ao conceito de "mentira organizada", apresentado por Arendt (1995), e o poder, sob esse viés, exerce-se através de um campo de opiniões, de "verdades" estabelecidas por essas narrativas, as quais são, portanto, sempre relativas. 
Em nossa pesquisa, observamos que a realidade dos/as jovens que circundam o CUCAJangurussu pode ser compreendida a partir dessa análise teórica, quando entendemos que se trata de uma parcela da população para a qual bens e garantias de direitos são negados. Discriminada pela cor da pele e alocada fora das fronteiras do direito à vida, ao alimento, à segurança, ao lazer etc., o que lhes resta? Há janelas abertas para esses/as jovens? Encontramos, até agora, políticas públicas também excludentes, germinadas pelas lógicas do martírio e da sobrevivência (Mbembe, 2017).

É necessário fazer uma observação no que diz respeito à questão de gênero. Embora também houvesse meninas nas margens do CUCA e em situação semelhante à dos meninos de que estávamos tentando nos aproximar, elas eram minoria e nenhuma chegou perto ou tentou conversar conosco. Este fato revela uma particularidade que tem a ver com as identificações de gênero, pois não é esperado de mulheres o envolvimento com a criminalidade e, quando isto acontece, parece haver uma dupla culpabilização da mulher: pelo crime suposto ou cometido e também por não corresponder ao socialmente previsto para o papel feminino.

\section{Políticas Públicas: Proteção ou Exclusão?}

Segundo Oliveira (2017), o Centro Urbano Cultural, Arte, Ciências e Esportes (CUCA) faz parte das políticas públicas culturais voltadas para jovens em Fortaleza, sobretudo para aqueles/as que vivem na periferia em uma situação de risco e vulnerabilidade social. Fundada em 2009, a rede CUCA é composta por três centros: CUCA Barra, CUCA Mondubim e CUCA Jangurussu. Atende a uma população juvenil com faixa etária de 15 a 29 anos, oferece cursos gratuitos como teatro, dança, música, comunicação, dentre outros, além de contar com uma equipe de profissionais formados para trabalhar com o público jovem, como educador/a social, assistente social, psicólogo/a, médico/a, enfermeiro/a e representantes de movimentos sociais da própria comunidade onde a instituição está inserida. As atividades do local são mantidas por verbas do poder público e pela sociedade civil.

Entendendo política pública como "ações governamentais dirigidas a resolver determinadas necessidades públicas" (Gelinsk, Ortiz, \& Seibe, 2008, p. 228), faz-se necessário pensar se o CUCA, como equipamento resultado de uma política pública voltada à juventude, atende às necessidades desses/as jovens que estão à margem da sociedade, da escola e, por 
consequência, não participam formalmente das atividades oferecidas pela instituição. Diante disso, surge um questionamento: a quem o equipamento beneficia?

Embora sendo de significativa importância para as comunidades periféricas da cidade e tenha possibilitado acesso à cultura, aos esportes e a cursos e informações a crianças, jovens e adultos com baixas condições socioeconômicas, há uma parcela juvenil que está à margem e que fica excluída até desses equipamentos nos seus territórios. Muitos dos eventos culturais, artísticos e profissionalizantes promovidos no local não chegam até esses/as jovens. Por estarem constantemente sob a mira de traficantes e da polícia, jovens, em sua maioria do gênero masculino, que de alguma forma são marcados como "indesejáveis" ou "inimigos" (tenham ou não cometido atos ilícitos), não conseguem se inserir nas atividades regulares. Embora no CUCA exista uma Diretoria de Defesa de Direitos Humanos (DDH), que busca trabalhar a partir da defesa de direitos dessa população que frequenta o espaço, não há uma ação efetiva para com esses jovens. Dessa forma, as atividades são direcionadas frequentemente a um público específico, que frequenta a escola e que tem uma rede de apoio familiar e social que favorece sua participação no CUCA. Porém, em relação ao público jovem que cumpre ou já cumpriu alguma medida socioeducativa, ou que esteja em conflito com a lei, esse equipamento público não tem conseguido atendê-lo em suas necessidades e especificidades. Muitas atividades exigem escolaridade mínima, disponibilidade de horários e possibilidade de circulação nas proximidades dos Centros. Além disso, a falta de uma consulta, em muitos casos, aos e às jovens sobre quais atividades seriam de seu interesse também é um fator que acaba por distanciá-los/as mais uma vez do equipamento. Dessa forma, como ressalta Oliveira (2017, s/p.):

As Políticas Públicas de Juventude (PPJ) atuam como forma de ajudar e colaborar no debate das mais variadas questões que permeiam os temas da sociedade como: raça, credo, gênero, classe social. As PPJ deveriam propiciar aos jovens uma formação que não seja apenas escolar, mas também ligada as áreas culturais, artísticas e esportivas. Desta forma, começa a se ter a construção social no seu conteúdo e conceito estratégico de sociedade. Outro ponto a ser considerado é que estas políticas públicas só surtem efeitos esperáveis quando é levada em conta a opinião do seu público alvo, ou seja, os sujeitos para os quais o benefício será propiciado, neste caso a juventude brasileira. (Oliveira, 2017, s/p) 
Assim, para se pensar políticas públicas para a população jovem em situação de vulnerabilidade social e econômica nas periferias de cidades grandes faz-se necessário, antes de tudo, conhecer e se aproximar dessa juventude periférica e marginalizada. Chegar até ela, entretanto, não é tarefa fácil, pois diante das experiências cotidianas de violência e discriminação que sofre, mostra-se desconfiada, reticente e pouco receptiva à aproximação. São estratégias de proteção e de resistência, inclusive para assegurar sua sobrevivência. É inegável que esses equipamentos criados em Fortaleza representam um significativo avanço dessas políticas para a população juvenil dos bairros onde estão instalados, mas para os/as jovens que caracterizam o perfil da nossa pesquisa (pobres, negros/as e marcados/as por uma aparência que os/as qualificam como "suspeitos/as" e socialmente indesejáveis) não há vontade política dos gestores, e mesmo de muitos profissionais que estão na execução direta dos serviços, para envolvê-los/as efetivamente nas ações que desenvolvem.

\section{Considerações Finais}

Nossa intenção com o presente artigo foi refletir sobre a realidade da juventude na periferia de Fortaleza, apresentando alguns índices acerca da violência urbana na capital cearense, bem como algumas narrativas trazidas por jovens que vivem em um contexto de profunda exclusão de direitos. Assim, nosso intuito foi apontar diversas situações que denotam os desafios de ser jovem negro/a e da periferia nessa cidade. Vimos que isso representa estar constantemente à margem da narrativa, isto é, em um lugar que desperta medo, desconfiança e ainda mais violência, seja esta física ou simbólica.

Consideramos ainda nosso esforço por nos debruçar em reflexões sobre o papel do Estado frente à situação de violência contra e entre os/as jovens na periferia, pois esse poder tem efetuado a manutenção dos mecanismos institucionais de exceção ao negligenciar a garantia de direitos fundamentais a uma parcela da população, notoriamente, pessoas negras e das comunidades periféricas.

Desse modo, observamos que as políticas públicas estabelecidas para essas pessoas, ao invés de promoverem inclusão e acesso à educação, à saúde e à segurança, por exemplo, acabam muitas vezes reproduzindo práticas excludentes. Daí, portanto, ser relevante que as pesquisas 
participativas se fortaleçam e gestem novos olhares sobre a realidade da periferia. Enquanto equipe de pesquisadoras mulheres em um campo dominado por diversas masculinidades - ora a performatividade intimidadora dos próprios jovens em ação, ora a performatividade truculenta da polícia - foi importante perceber que o primeiro significado de uma pesquisa participativa com jovens desse território seria a vivência do desafio de nos aproximarmos desses sujeitos.

Nesse texto, mais do que responder, acabamos por aprofundar a pergunta norteadora de nosso estudo, "como jovens negros, excluídos da escola e de outros equipamentos sociais de Fortaleza, significam e reagem à exclusão social e à ameaça à própria vida?”. Através de conversas informais, relatos orais e observações - aspectos metodológicos que serão desenvolvidos em outros escritos - entendemos que criar condições (inovadoras, desafiadoras e por vezes arriscadas para os/as pesquisadores/as) de escuta dos jovens que lá vivem e experienciam cotidianamente os processos de violação e negação de direitos compõe o compromisso ético-político de ruptura com o ciclo de silenciamento e negação da existência da juventude pobre, preta e periférica.

\section{Referências}

Arendt, H. (1995). Verdade e política. Lisboa: Relógio D’Água.

Cerqueira, D., Lima, R. S., Bueno, S., Neme, C., Ferreira, H., . . Coelho, D. (2018). Atlas da Violência 2018. Rio de Janeiro: IPEA, Fórum Brasileiro de Segurança Pública.

Chacina da Messejana: PM's fizeram cerco para matar, diz investigação. (2016, setembro 2). $O$ Povo. Fortaleza. Recuperado de http://www.opovo.com.br/app/opovo/cotidiano/2016/09/02/noticiasjornalcotidiano,36557 32/chacina-da-messejana-pms-fizeram-cerco-para-matar-diz-investigacao.shtml Comitê Cearense pela Prevenção de Homicídios de Adolescentes [CCPHA]. (2016). Cada Vida Importa: Relatório Final. Fortaleza: Governo do Estado do Ceará, Assembleia Legislativa do Estado do Ceará e Instituto OCA. Recuperado de https://cadavidaimporta.com.br/publicacoes/relatorio-final-cada-vida-importa/ Comitê Cearense pela Prevenção de Homicídios de Adolescentes. (2018). Cada Vida Importa: Relatório do primeiro semestre do ano de 2018 do Comitê Cearense pela Prevenção de 
Veriana de Fátima Rodrigues Colaço, Luciana Martins Quixadá, Jaileila de Araújo Menezes, Ana Jéssica de Lima Cavalcante, Raquel Nascimento Sousa

Homicídios de Adolescentes. Fortaleza: Governo do Estado do Ceará, Assembleia Legislativa do Estado do Ceará e Instituto OCA.

Ferreira, I. C. B., Vasconcelos, A. M., \& Penna, N. A. (2008). Violência urbana: A vulnerabilidade dos jovens da periferia das cidades. São Paulo: Abep. Recuperado de http://www.ceam.unb.br/oj/arquivos/artigo_nogales.pdf

Fórum Brasileiro de Segurança Pública [FBSP]. (2016). 10 Anuário brasileiro de segurança pública, $\quad 10,1-138 . \quad$ Recuperado de https://forumseguranca.org.br/storage/10_anuario_site_18-11-2016-retificado.pdf

Foucault, M. (2016). Em defesa da sociedade. São Paulo: WMF Martins Fontes.

Geertz, C. (2008). Obras e Vidas: O antropólogo como autor (2a ed). Rio de Janeiro: UFRJ.

Gelinski, C. R., Ortiz. G., \& Seibe, E. J. (2008). Formulação de políticas públicas: Questões metodológicas relevantes. Revista de Ciências Humanas, 42(1-2), 227-240. doi: 10.5007/2178-4582.2008v42n1-2p227

IPECE. (2013). Perfil da Juventude em Fortaleza: Aspectos socioeconômicos a partir dos dados do censo 2010. IPCE Informe, (57), 1-20. Recuperado de https://www.ipece.ce.gov.br/wpcontent/uploads/sites/45/2012/12/Ipece_Informe_57_22_abril_2013.pdf

Mayorga, C., Diniz, A. R., Pinto, G. P., Borges, L. A., Lino, T., \& Rodrigues, T. (2015). Juventude Negra e Movimento Negro Brasileiro: Contínuos históricos e tensões no contexto de Belo Horizonte. In A. Scisleski \& N. Guareschi (Orgs.), Juventude, Marginalidade Social e Direitos Humanos: da Psicologia às Políticas Públicas (pp. 75-94). Porto Alegre: EDIPUCRS.

Mbembe, A. (2011). Necropolítica: Seguido de Sobre el gobierno privado indirecto. Tenerife: Melusina.

Mbembe, A. (2017). Políticas da inimizade. Lisboa: Antígona.

Oliveira, R. F. V. (2017). O uso do espaço urbano, por meio das políticas públicas de cultura para a juventude: $\mathrm{O}$ caso do centro urbano de cultura, arte, ciência e esporte - Cuca Barra. Fortaleza. Anais do III Seminário Regional Comércio, Consumo e Cultura nas Cidades. Sobral, Ceará, Brasil.

Santos, D. D., Jorge, D. R. S. R., \& Souza, E. R. (2017). O paradoxo da política de segurança pública: Estado, PCC e a gestão da violência na cidade de São Paulo. Primeiros Estudos, (8), 105-124. doi: 10.11606/issn.2237-2423.v0i8p105-124 
Veriana de Fátima Rodrigues Colaço, Luciana Martins Quixadá, Jaileila de Araújo Menezes, Ana Jéssica de Lima Cavalcante, Raquel Nascimento Sousa

Spink, P. K. (2003). Pesquisa de campo em Psicologia Social: Uma perspectiva pósconstrucionista. Psicologia \& Sociedade, 15(2), 18-42. doi: 10.1590/S010271822003000200003

Waiselfisz, J. J. (2016). O Mapa da Violência: Adolescentes de 16 e 17 anos. Rio de Janeiro: FLACSO Brasil.

Werneck, J. (2014). Intersecções de raça/etnia, gênero e classe: Faces cotidianas e teóricas. In G. O. Assis, L. S. Minella, \& S. B. Funck (Orgs.). Entrelugares e mobilidades (pp. 319-328). Tubarão: Copiart.

\section{Endereço para correspondência}

\section{Veriana de Fátima Rodrigues Colaço}

Rua Henriqueta Galeno, 960 apto. 201, Dionísio Torres, Fortaleza - CE, Brasil. CEP 60135-420

Endereço eletrônico: verianac@gmail.com

\section{Luciana Martins Quixadá}

Rua José Vilar de Andrade, 1750 casa 18, Sapiranga, Fortaleza - CE, Brasil. CEP 60833-096

Endereço eletrônico: luciana.martins@uece.br

\section{Jaileila de Araújo Menezes}

Rua Paraguassu, 62 apto. 102 bloco A, Zumbi da Torre, Recife - PE, Brasil. CEP 50711-020

Endereço eletrônico: jaileila.araujo@gmail.com

\section{Ana Jéssica de Lima Cavalcante}

Rua Ramos Botelho, 129 apto. 606, Papicu, Fortaleza - CE, Brasil. CEP 60175-265

Endereço eletrônico: ajessica.cavalcante@gmail.com

\section{Raquel Nascimento Sousa}

Rua Florêncio Fontenele, 342 bloco C apto 101, Jangurussu, Fortaleza - CE, Brasil. CEP 60865-000

Endereço eletrônico: raquelnascimentosss @ hotmail.com

\section{Recebido em: 20/09/2019}

Reformulado em: 10/09/2020

Aceito em: 05/10/2020 
Veriana de Fátima Rodrigues Colaço, Luciana Martins Quixadá, Jaileila de Araújo Menezes, Ana Jéssica de Lima Cavalcante, Raquel Nascimento Sousa

\section{Notas}

* Graduada em Psicologia. Mestre em Educação e Doutora em Educação. Pós-doutorado em Psicologia. Professora Titular da Universidade Federal do Ceará.

** Graduada em Psicologia. Mestre em Psicologia e Doutora em Educação Brasileira. Professora Adjunta da Universidade Estadual do Ceará.

*** Graduada em Psicologia. Mestre em Psicologia e Doutora em Psicologia. Professora Adjunta da Universidade Federal de Pernambuco.

**** Graduada em Psicologia. Mestre em Psicologia. Psicóloga do Programa Rede Acolhe, da Defensoria Pública do Ceará.

***** Psicóloga formada pela Universidade Federal do Ceará.

${ }^{1}$ O Comitê é uma iniciativa conjunta da Assembleia Legislativa do Ceará, Governo do Estado do Ceará e Fundo das Nações Unidas para a Infância (UNICEF), criado com o objetivo de compreender o fenômeno da violência entre os jovens - com foco na faixa etária de 10 a 19 anos - para, a partir daí, elaborar propostas de políticas públicas que apontem para a prevenção e a redução de homicídios cometidos por adolescentes e contra adolescentes no Ceará.

Este artigo de revista Estudos e Pesquisas em Psicologia é licenciado sob uma Licença Creative Commons Atribuição-Não Comercial 3.0 Não Adaptada.

Estud. pesqui. psicol., Rio de Janeiro, v. 21, n. 2, p. 474-493, 2021. 